\title{
Seasonality in a Savanna District of Ghana-Perceptions of Women and Health Workers
}

\author{
Gill Gordon
}

These notes on seasonality arise from a rapid rural appraisal carried out for UNICEF in the Dangbe district of Ghana in July and August 1984. The appraisal focused on UNICEF's GOBI-FFF ${ }^{1}$ strategy and addressed the following questions:

- What do mothers know and do about growth monitoring, diarrhoea, breastfeeding and weaning, immunisation and family planning? How have they adapted their practices to changing economic and household situations and to new knowledge?

- What do health workers know and do about the GOBI-FFF activities? How is their ability to implement the strategy affected by the economic situation in Ghana?

- What is the potential for individuals and organisations in the community to become involved in GOBI activities?

- What other important interventions are required to enable parents to protect the health and growth of their children?

\section{Methodology}

Data were collected from a variety of sources. Resource constraints often made it necessary to share transport with health workers and to hold group discussions with women gathered at clinics all over the district, rather than in a random selection of villages. However, several villages from each of three types were visited and over a half of the women in group meetings were attending the clinic for the first time.

Seventy-four mothers of pre-school children were interviewed in their homes using a semi-structured questionnaire. Questions covered the occupations of household members; who provided most of the food for the children; problems with farming and trading

1 GOBI-FFF is an acronym for growth monitoring, oral rehydration, breastfeeding, immunisation, food supplements, family planning and female education. UNICEF has identified these as priority activities for improving child survival and development globally. and how these might be tackled; strategies for managing childcare and work, changes in childrearing since their mothers' generation and reasons for these changes.

Discussions were held with 15 groups of women, ranging in age from 18 to 60 years, in 10 villages. A check list of questions was used to stimulate discussion, which was recorded. The optimal number of women was 15 to 20 , although it was sometimes difficult to exclude other women who wanted to join the group. Larger groups made it difficult to keep to the point and give everyone a chance to talk. Men were excluded because they invariably dominated the discussion, criticised women's contributions and attributed their problems to ignorance and negligence rather than resource constraints. Focus group discussions lasted for at least an hour and often longer because requests for information were responded to fully, and issues explored further as they arose.

Health workers at district and village level were interviewed individually and in small groups.

Health service statistics were analysed from child welfare clinics, outpatient departments, community clinics and hospital admissions.

Seventy-five mothers attending the malnutrition clinic were interviewed to elicit their views on the reasons for the child's poor growth and their socio-economic situation.

\section{Setting}

The economy of Ghana has been deteriorating since the 1970s. In 1982 a four year recovery plan was drawn up, financed by a conditional IMF loan. 1983 was a year of severe hardship and hunger, due to a combination of factors - drought, bush fires, the influx of one million Ghanaians from Nigeria, petrol shortages and a reduction in the electricity supply caused by falling levels in the Volta Lake. In June, 


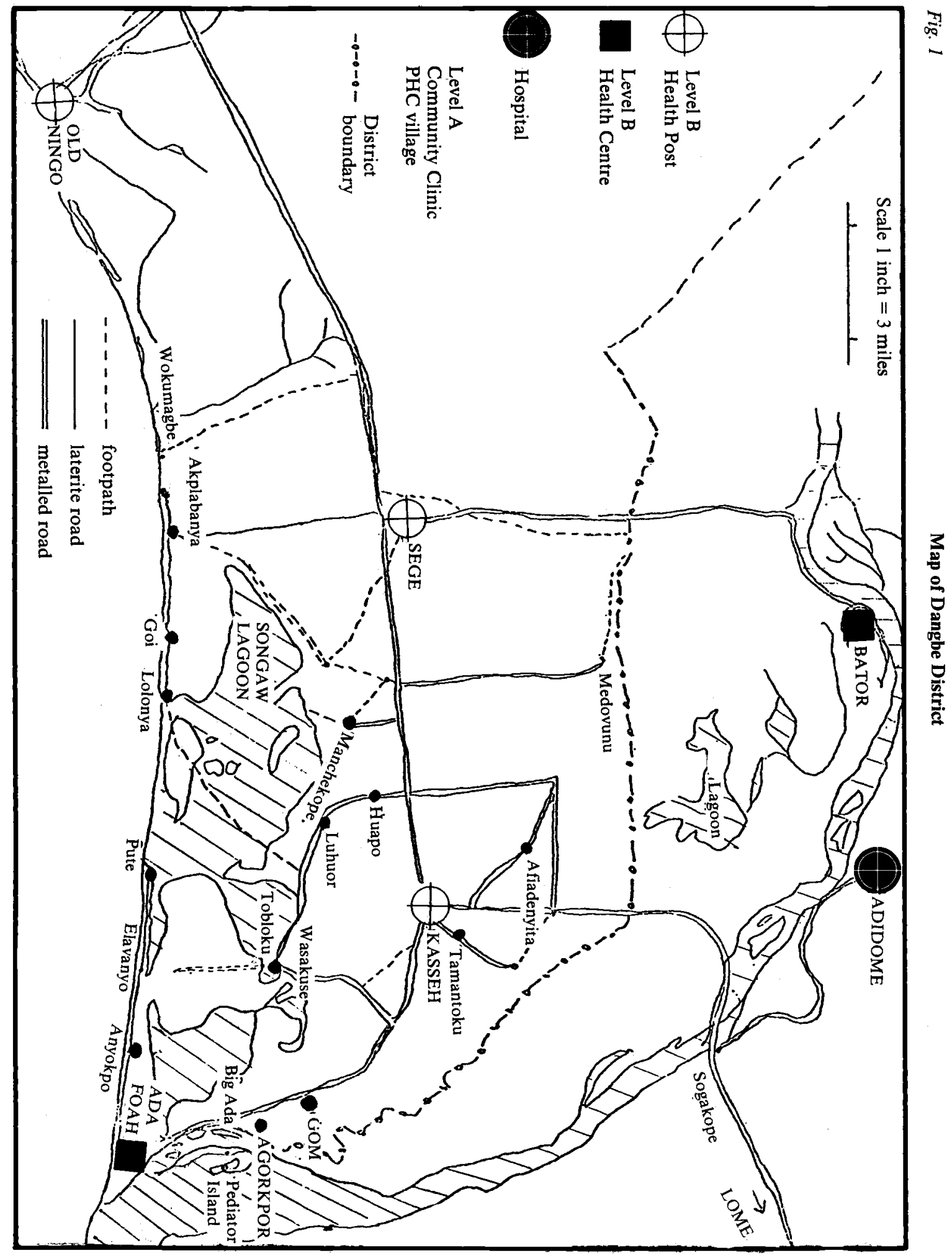


coconuts, groundnuts and water became the staple foods and jokes were made about 'Rawlings necklace', the protruding collar-bones of even those professionals who could not find a way to leave the country. The price of food rocketed, and emergency food aid was brought in until August 1984. Normal seasonal fluctuations in food prices were no longer relevant as staggering rises occurred from week to week as prices were allowed to find their own level.

Dangbe district has a population of around 70,000 with a male:female ratio of $100: 110$. The district lies in the coastal Savanna belt, with a bimodal rainfall pattern, from March to July and September to October. There are three main types of villages in the district:

- coastal villages, where the men fish and the women smoke the fish for sale. Cassava, tomatoes and shallots are grown in the sandy soils.

- inland villages on lagoons or on the Volta River, with sandy soils. Fishing and the cultivation of cassava, tomatoes, sugar cane and shallots are the main occupations.

- inland villages in the north of the district where groundnuts, beans, maize, pepper and tomatoes are grown in the more fertile soils.

\section{The Household Economy}

Forty-eight per cent of the households visited were headed by women, the majority because the husband lived in another town, or with another wife. In these households, the women provided most or all of the food for her children. In the other households, the contributions of members to the food supply, and the strategy employed to ensure survival depended on the season and the ecology of the village. The majority of women aim to farm and trade, but deteriorating soils, unreliable rainfall, a lack of agricultural inputs and plant disease, makes trading a more attractive option. In the preharvest season the majority of women would invest extra cash in their trades. They were extremely interested in ways to acquire credit. One group said that it was difficult to run an informal credit scheme where women paid in a fixed sum each month, because at certain times of the year women would be unable to pay. During the clearing season, more women may have preferred to invest money in tractor hire, fertilizer and seed.

In coastal villages men catch the fish and women purchase it from them through an agent. The women then smoke the fish and sell it using the profits to feed themselves and their children. The supply of fish is affected by the season and the activities of trawlers from the USSR and other countries further out to sea.
When the sea is rough the fishermen stay at home. Fish catches decline in the dry season and families move up the coast to Lome or Tema to follow the fish. According to the community clinic attendants (CCA), many children return from these journeys with malnutrition and infections, because they have lived in temporary accommodation with poor quality care.

An improved fish smoker has enabled women to increase their profits by reducing firewood consumption and improving the quality of the product. The smoker improves fuel efficiency by increasing the capacity of the oven, which means that groups of women need to pool their baskets of fish in order to utilise the extra capacity, particularly in times of seasonal shortages. Dangbe women appear to be willing to cooperate in this way, but a group of Ewe women admitted that they were too competitive and mistrustful to work together. When fish became scarce, men could command exorbitant prices because 'if one woman refused to pay, another was ready to jump in and pay even more'. In a village further along the coast, the improved smokers were often underutilised because of inadequate fish supplies. Seasonalty of supplies and migration need to be taken into account when new processing technologies are introduced. Inadequate supplies of raw materials, related to season, are a major problem with improved food processing technologies in Ghana [ILO 1984], and result in new equipment being overcapitalised and underutilised.

Wasakuse is an inland village on a lagoon, with sandy soils. Women aim to farm and trade in order to maintain a constant source of food and cash. Several years of droughts and deteriorating soils are severely limiting their economic opportunities. The cassava, tomatoes and shallots were clearly failing by the end of July 1984. The water level in the lagoon had sunk so low that fishing was no longer viable and the women could not fry fish for sale. The sale of pigs and goats was the only source of income and disease had undermined even this. Women thought that around half the families in the villages would migrate out of the district northwards to the forest belt around A kosombo to farm by the end of August. They would live in temporary shelters, remote from health care, and the women expected this to have a negative effect on the growth and health of young children.

Further north, farmers grow a mixture of crops, often maize, cassava, beans, groundnuts, tomatoes and peppers. During the preharvest season, the women's trading activities support the household. After the harvest, the husband may contribute a larger amount of food from his farm. Men have greater access to tractors for clearing, fertiliser and land. They are more likely to belong to a farmers' association and see an 
extension officer. However, trading in the preharvest season is competitive and time-consuming. Purchasing power in the community is low, many women sell the same commodity, and supplies of raw materials, for example, maize, are expensive and difficult to obtain. Kenkey ${ }^{2}$ sellers in one village formed an association to buy maize cheaply in bulk and ensure a regular supply. Many other women traders expressed a need for credit which would enable them to secure supplies of raw materials for their trade.

\section{Seasonality and Primary Health Care}

Primary healthcare is expanding rapidly in Ghana in the form of community clinics. These are staffed by community clinic attendants (CCAS) usually young male farmers from the village. They are expected to treat patients at the clinic and promote healthy behaviour in the village on a part-time basis, for a salary of around $\mathrm{C} 600 .^{3}$ (A doctor's salary is $\mathrm{C} 1,500$.) The salary comes from the sale of drugs to patients, administered by the village health committee.

The CCAs had several problems with their work, which would exacerbate in the farming season. They complained that health activities were seriously interfering with their farming. Not only attending to patients but the many journeys to Ada Foah for supplies and advice was time-consuming. Moreover, demand for curative care was at its peak in the rainy season when farmers tasks were not pressing.

Income accruing from the sale of drugs was precarious because people had no spare cash at this time of year and often promised to pay later. Also, the health committee functioned poorly or ceased altogether as members migrated or became overwhelmed with their own concerns. Drug supplies and payment became unreliable.

The financial advantage to many CCAs clearly lay in the farm rather than the clinic. Several CCAs requested bicycles to enable them to return to the clinic earlier from their distant farms.

The CCAs are expected to be part-time health workers but in fact those employed by the Ministry of Health are also obliged to supplment their inadequate income with farming, trading, private practice or donated foods. If many health workers farm, they will also be unwilling to work a full day attending to the extra numbers of patients at the clinics. They will be most tempted to appropriate aid foods when foods are scarce and expensive in the local markets, at the time when they are most needed by their malnourished clients.

\footnotetext{
${ }^{2}$ Kenkey is a fermented boiled maize product eaten as a main meal with fish.

${ }^{3} 56$ Cedis $=£ 1.00$.
}

\section{Seasonality and GOBI Growth Monitoring}

At present growth monitoring, advice on breastfeeding and weaning, and immunisations are offered at Maternal and Child Health (MCH) Clinics in 16 locations, once a month. Food supplements are also given to selected mothers, according to criteria laid down by the Catholic Relief Services (CRS), which change from time to time. Treatment for diarrhoea is available at any time from the community clinic or the health post, but not the MCH Clinic.

The costs and benefit of clinic attendance as perceived by the mother are likely to vary seasonally. In the rainy season, women are busy with trading and farming, and this may involve travelling for a period of time. Money for fares and fees is scarce. With high costs, the benefits must be worthwhile. Women said that a good chance of a reasonable amount of desirable food was the most attractive benefit offered by the clinics in the hungry season. Mothers and health workers agreed that it would not be worth attending the clinic for weighing and advice only because most mothers were aware of their child's progress and needs.

Thirty-nine per cent of the children attending the malnutrition clinic had never attended before, and over 60 per cent of these had mothers who had migrated to Asosombo, or travelled long distances with their work. Twelve per cent of the malnourished children had not been weighed for several months before reporting to the clinic. (This means that malnutrition had not been prevented by growth monitoring in half of the children.) Several of the migrant mothers said that they had returned to attend the clinic because of their concern over the child's poor growth and failure to respond to treatment away from home. The question is whether they could be helped to monitor their child's progress more efficiently in order to pick up faltering growth earlier while they are out of contact with the clinic, and also, whether they could afford to respond to smaller monthly fluctuations in weight, given the needs of the rest of the family.

Seasonal variations in weight for age should have shown up in the monthly statistics collected for CRS, Accra. Unfortunately, these data are not kept at district level for local use, and, CRS rejected five out of 12 months in the previous year as unreliable. Two few deliveries were carred out at health units to analyse seasonal trends in birthweight.

However, there is plenty of anecdotal evidence from health workers and focus groups that seasonal stress has an important effect on nutritional status. CCAs, nurses and mothers said that children returning from seasonal migration along the coast and northwards 
present with malnutrition and infections because of poor quality care and rough conditions. The hungry season, when palmnuts, groundnuts and fish are scarce, was a time of poor growth in children.

In Wasakuse women said in the season of plenty, children eat fish stew every day and grow well. In the lean season there is not much of anything and everyone must eat pepper with their cassava. Whatever their age, there is no discrimination, then, the children stop growing'. Numbers attending, the malnutrition clinic increased over the rainy season in 1984, partly because of a lack of food, and partly because of the sequel to a measles epidemic.

\section{Oral Rehydration}

Death from diarrhoea can be prevented if children are given plenty of fluids as soon as the diarrhoea starts, and treated with oral rehydration solution (ORS) at the first sign of dehydration. Carers can be taught to make up a solution using salt and sugar, or use a UNICEF sachet of ORS at home.

Seasonal trends in the incidence of diarrhoea did not show up in health service statistics, but one would expect more cases to occur in the rainy season. It is important to teach everyone responsible for daily childcare, whether grandmother, mother, daughter or migrant mother, to make up and give rehydration fluid correctly at the first sign of diarrhoea. If the mother does not have time to sit with the child offering sips of fluid, the carer must do it. If migrant families are far from a health unit, they need to carry their own supply of sachets or salt and sugar. People need to recognise signs that the child is becoming dehydrated in spite of the fluid and that they must seek more help.

\section{Breastfeeding and Women}

Women individually and in groups described how breastfeeding and weaning practices have changed since their mothers' generation. Children are now given supplementary foods, particularly maize gruel, much earlier, and breastfeeding stops earlier. Only six percent of the mothers practised the exclusive breastfeeding recommended by UNICEF for the first four months of life, and 22 per cent had introduced pap before the child was one month old. Individual mothers stated that they personally had given a particular child pap at two weeks because it was not satisfied with breastmilk only. In the focus groups, many women laughed at this reason, and said that women in general gave pap early because they were anxious to return to their trading and farming. They wanted the child to become less dependent as soon as possible. One group of health workers also believed that the very short rest women were able to take after delivery, anxiety, lack of traditional support from men, and a poor quality diet were resulting in a decline in breastmilk production.

If this economic explanation of early supplements is correct or partially correct, one can expect seasonal stress to exacerbate the problem, when women are anxious to start work at their farms and trades.

One of the CCAs advises mothers to take their young children with them to the farm with an older sibling. They can make shades against the sun, and feed them on the farm. Some women and health workers give a different explanation for the earlier supplements and cessation of breastfeeding. They believe that mothers have learnt about breastmilk substitutes - beverages, homemade weaning mixes, baby foods - through the health service, the media, school and travel. They are aware that they do not have to be glued to the baby day and night for months, that there are alternatives which free a mother from total responsibility for feeding. This knowledge of breastmilk substitutes also enables these mothers to contemplate weaning at one year rather than waiting for two or three years as their mothers did.

Unfortunately, the extent to which mothers are able adequately to substitute for breast milk depends on the time, cash and foods at their disposal. As one woman said 'the poorest mothers are under the most pressure to go back to work early, work long hours, travel, and wean the child. But they are the least able to afford good breastmilk substitutes'.

Health workers advise mothers to add fish powder or groundnut paste to the maize pap, and sell packets of fish powder at the clinics. Mothers appreciated the convenience of this, but in the hungry season the price of fish rose so steeply that the sales had to stop. (Other programmes involved in marketing weaning food have run into similar problems with seasonal scarcities of raw materials, at a time when the weaning foods are most needed.) Health workers at one health centre finally stopped giving advice on feeding to mothers because they themselves could not afford to buy the food for their own children.

The majority of women continue to breastfeed for around 18 months, but the loss of a source of high quality protein and fat will be felt, particularly in the hungry season. Nineteen per cent of the children attending the malnutrition clinic were cared for by the grandmother or aunt because their mother had migrated. These children had been weaned at around one year, and were reported to be miserable, anorexic and frequently sick. If their mothers were pushed into leaving the district by seasonal stress, this would further add to the problems of the child and guardian because food would be scare and the guardian busy. 
A further 19 per cent of the children at the clinic had mothers who travelled frequently with their work. Again, the hungry season would be a time when mothers were under pressure to travel while conditions were least favourable for the child at home.

\section{Seasonal Patterns of Disease and Immunisation}

Statistics from the outpatient department at Ada Foah Health Centre did not show any seasonal trends. Malaria is endemic in the district, and accounts for more outpatient visits, hospital admissions and deaths than any other disease.

There are epidemics of measles and whooping cough, but these are not reflected in outpatient statistics because the clerks record symptoms rather than diseases. Measles might be entered as fever, diarrhoea, cough or rashes depending on the mother's initial complaint.

Mothers who are aware that immunisation is sometimes available at the $\mathrm{MCH}$ Clinic are more likely to attend when cases of measles or whooping cough increase in the area, or at times when epidemics are known to occur. At this time the risks to the child of catching a severe illness are perceived to outweigh the risks of acquiring an abscess of hepatitis from an unsterilised needle, or of 'catching another disease, which one can't afford to treat' at the clinic. A measles epidemic had occurred at the beginning of the 1984 rainy season, when women were least able to spare time from planting.

Malnutrition was associated with measles, whooping cough or diarrhoea in 63 per cent of the children attending the malnutrition clinic, and 72 per cent of the malnourished children seen in the home. Respiratory tract infections also increase during the rainy season.

\section{Policy Implications}

Seasonal stress emerges as an important dimension both in primary health care and in the ability of women to manage their economic and reproductive roles in Dangbe district. Although specific questions on seasonality were not asked, groups of women and health workers repeatedly brought the topic up in discussion.

The impact of seasonality, and therefore the policy implications, vary with the type of village. Children in coastal and inland or riverside villages with sandy soils appear to be at high risk of malnutrition because many families are obliged to migrate. Children in inland villages with more fertile soils do not have to cope with the stress of migration.
This rapid appraisal provides some pointers to seasonal stresses, but development workers within the district need to study these with the community in greater depth, and then look for ways of reducing this impact or at least of protecting child health wherever possible. This study would involve discussion with groups in the different types of village, using a check list of questions which might include the following:

- which families migrate and why?

— do families migrate in groups?

- where do migrant families live, what do they eat, what health services do they use, and what problems do they encounter?

- what are the reasons for many children becoming thin and sick when they migrate?

After analysis of the problems, groups would go on to look for ways to improving the situation. These might include:

- measures which reduce the need to migrate: for example, irrigation; fish ponds; crop varieties suited to dry sandy soils; improved small animal husbandry; action to enhance soil fertility; credit technology and marketing to increase women's trading profits; dry season gardens.

- measures to improve living conditions for migrant families.

- measures to protect the health of young children. For example:

- immunise children before they migrate;

- teach parents how to give coconut water or prepare oral rehydration solution and supply ORS sachets;

- make antimalarials available;

- teach someone in each group to weigh or measure children;

- discuss ways of best preparing a diet suitable for young children;

- encourage families to seek out and use the nearest health facilities.

Further discussion and study is needed on the operation of the primary health care programme in relation to season. The conflicts of interests between farming and health work need a serious response otherwise the viability of the new programmes is in jeopardy. Bicycles for the CCAs; actions to stabilise their pay and to reduce their need to travel for supplies and supervision in the rainy season; an exploration of ways to share the health work between CCAs, and for community members to contribute to the CCAs 
farms; and the selection of at least some non-migrant members on the health committees are some possibilities.

As far as possible MCH services should be carried out in the community, and young or elderly childminders should be encouraged to attend.

Women might consider setting up daycare centres in the rainy season.

The health service should respond to an expressed need for family planning to enable women to achieve a longer birth interval and a smaller family size, and to avoid pregnancy during periods of economic stress.

\section{References}

ILO, 1984, Technological Change, Basic Needs and the Condition of Rural Women, Geneva, June

Tomilayo, Adekanye O., 1985, 'Innovation and rural women in Nigeria: cassava processing and food production' in I. Ahmed (ed.), Technology and Rural Women, George Allen and Unwin, London 